\title{
Educação ambiental e justiça social: reflexões em tempos de solidão democrática
}

\author{
Environmental education and social justice: reflections in times of democratical solitude
}

\author{
Educación ambiental y justicia social: reflexiones en tiempos de soledad democrática
}

Vilmar Alves Pereira*

Simone Grohs Freire*

\section{Resumo}

O presente texto busca refletir, criticamente, a partir da Educação Ambiental Crítica, acerca da concepção de justiça social. Para tanto, propõe-se trazer ao debate uma perspectiva histórico-política da democracia e da cidadania no cenário brasileiro como possibilidades não apenas de compreensão do atual cenário posto, como também de uma releitura das relações socioambientais, que definem a realidade contemporânea. Este diálogo tem como base a concepção hermenêutica de Gadamer, enquanto um processo universal do compreender que problematiza o não dito, oferecendo uma perspectiva de abertura, para que se possa pensar sobre nós mesmos e sobre qual é o nosso lugar no mundo. Espera-se, ao final, ter promovido uma reflexão crítica e dialógica acerca da realidade para uma ação em busca de justiça social, ainda tão negada.

Palavras-chave: Cidadania. Educação ambiental. Justiça social.

\section{Abstract}

The present text seeks to critically reflect, from the point of view of Critical Environmental Education, about the conception of Social Justice. Therefore, a historical-political perspective of democracy and citizenship in the Brazilian scenario is brought up to the debate, as a possibility not only for understanding the current scenario, but also as a re-reading of the socio-environmental relations that define contemporary reality. This dialogue is based on Gadamer's hermeneutic conception of a universal process of understanding which problematizes the 'unsaid', offering a perspective of openness so that we can think about ourselves and about our place in the world. In the end, it is hoped to have promoted a critical and dialogic rethinking of reality so that one can act in search of a social justice still extremely denied.

Keywords: Citizenship. Environmental education. Social justice.

Recebido em 25/03/2019 - Aprovado em 01/07/2019

http://dx.doi.org/10.5335/rep.v26i3.9325

Doutor em Educação pela Universidade Federal do Rio Grande do Sul. Coordenador e pesquisador no Programa de Pós-Graduação em Educação Ambiental da Universidade Federal do Rio Grande. Bolsista de Produtividade em Pesquisa do Conselho Nacional de Desenvolvimento Científico e Tecnológico, nível 2. Brasil. ORCID: 0000-0003-25485086. E-mail: vilmar1972@gmail.com

* Doutora em Educação Ambiental pela Universidade Federal do Rio Grande. Professora da Faculdade de Direito e do Programa de Pós-Graduação em Educação Ambiental da Universidade Federal do Rio Grande. Brasil. ORCID: 00000003-3566-0669. E-mail: simonefreire@furg.br 


\title{
Resumen
}

\begin{abstract}
El presente texto busca reflexionar, críticamente, desde la Educación Ambiental Crítica, acerca de la concepción de la Justicia Social. Por lo tanto, se propone llevar al debate una perspectiva histórico-política de la democracia y de la ciudadanía en el escenario brasileño, como posibilidades no sólo de comprensión del actual escenario puesto, sino también de una relectura de las relaciones socioambientales que definen la realidad contemporánea. Este diálogo tiene como base la concepción hermenéutica de Gadamer, mientras que un proceso universal de comprender que problematiza lo "no dicho", ofreciendo una perspectiva de apertura, para que podamos pensar en nosotros mismos y en cuál es nuestro lugar en el mundo. Al final, se espera haber promovido un replanteamiento crítico y dialógico de la realidad, para que se pueda actuar en busca de una justicia social aún tan negada.
\end{abstract}

Palabras clave: Educación Ambiental. Ciudadanía. Justicia social.

\section{Introdução}

Estes são tempos marcadamente de inúmeras injustiças sociais; tempos em que as racionalidades únicas fundamentalistas buscam encolher os avanços democráticos em todas as esferas. Aqueles avanços conquistados com muita organização e luta, no campo das questões sociais, estão agora sendo violentamente ameaçados. Ancorada no discurso de que as políticas sociais cometeram exageros por permitirem o reconhecimento de milhares de brasileiros que se encontravam e se encontram na inviabilidade, a lógica hegemônica da extrema direita reapresenta suas faces, buscando mais um retorno a posturas de adestramento e domesticação do que possibilidades emancipatórias.

No que concerne ao campo e às conquistadas da Educação Ambiental (EA), são mais de 30 anos de lutas, para que as questões voltadas à EA fossem reconhecidas e, posteriormente, passassem a integrar as diretrizes curriculares de ensino em todos os seus níveis. Como resultados dessa luta, destacam-se: 1) a Política Nacional do Meio Ambiente, de 1981; 2) a Lei de Diretrizes e Bases da Educação Nacional, de 1996, que reconhece a EA; 3) a Lei no 9.795, de 27 de abril de 1999, regulamentada pelo Decreto no ${ }^{\circ} .281$, de 25 de junho de 2002, que dispõe, especificamente, sobre a EA e instituiu a Política Nacional de Educação Ambiental (PNEA) e seu órgão gestor; 4) as resoluções do Conselho Nacional de Educação, como a n ${ }^{\circ} 2 / 2012$, que estabelece as Diretrizes Curriculares Nacionais para a Educação Ambiental, e a no 2/2015, que estabelece as Diretrizes Curriculares Nacionais para a Formação Inicial e a Formação Continuada de Professores, entre muitas outras normativas que vêm sendo construídas, participativamente, pela larga comunidade de educadores ambientais. Na atual conjuntura, vivem-se períodos de intensa preocupação, para manter as referidas garantias, diante do discurso e de práticas deste governo. 
Em recente movimento internacional, educadores ambientais de todo o mundo se posicionaram, por meio de uma carta endereçada aos ministros da educação e do meio ambiente, contra algumas medidas do atual governo, que geram injustiças à nossa história e às nossas garantias. De modo geral, o documento critica a mitigação do papel da EA no Decreto no ${ }^{\circ}$ 9.665/2019, que a vincula a uma secretaria do ecoturismo, voltada para simples campanha de conscientização ambiental. Também limita o reconhecimento da EA como tema transversal, além de restringi-la à educação básica, por meio do Decreto no 9.665/2019. Preocupa, igualmente, o fato de os Decretos no 9.665/2019 e no 9.672/2019 não fazerem menção à Lei oㅜ 9.795/1999, a qual define a PNEA e as atribuições do Poder Público em todos os níveis, especificamente do Ministério do Meio Ambiente e do Ministério da Educação. Esses são apenas alguns sinais de que a democracia brasileira se encontra em risco, e, de modo geral, pode-se estar comprometendo a dignidade humana em diferentes processos.

Desse modo, quando se fala em EA neste estudo, assume-se o horizonte de uma Educação Ambiental Crítica, por reconhecer que neste texto se revisitam alguns movimentos no campo da EA, e, posteriormente, assumem-se alguns desafios no sentido de pensar possibilidades de uma justiça socioambiental, que pela sua natureza está relacionada ao enfrentamento de todas as tentativas de encolhimento da vida digna.

\section{Que educação ambiental? Uma análise do cenário democrático (?) brasileiro}

O reconhecimento e a institucionalização da EA no cenário brasileiro se deram a partir da década de 1990, com a criação da PNEA e, posteriormente, também do plano infraconstitucional, com outras medidas que se somaram a essa política. Pode-se dizer que a EA atingiu seu ponto culminante com a Constituição federal de 1988, que, além de instaurar o modelo democrático no país, ambientalizou o sistema legal, ao estabelecer o direito ao meio ambiente ecologicamente equilibrado como direito fundamental.

Ocorre que, vindo de uma longa tradição autoritária, a partir de 1988, o Brasil rompe com esse modelo e inaugura uma nova tradição, a democrática. O Estado Democrático de Direito ultrapassa a ideia de um Estado Social, porque, além de promover a igualdade formal (perante a lei), busca a concretização da igualdade material por meio da efetivação dos direitos fundamentais. Pode-se dizer, portanto, que o Estado Democrático de Direito é o modelo de consagração dos direitos fundamentais, os quais, por sua vez, estão ancorados no princípio da dignidade da pessoa humana, 
objetivo fundamental da Constituição federal brasileira. Assim, a dignidade da pessoa humana deve ser considerada o elemento comum, unificando todos os direitos fundamentais, enquanto esses, no que lhes diz respeito, são uma concretização do fundamento em si. Os direitos fundamentais podem ser compreendidos como:

[...] a facultad que la norma atribuye de protección a la persona en lo referente a su vida, a su libertad, a la igualdad, a su participación política o social, o a cualquier otro aspecto fundamental que afecte a su desarrollo integral como persona, en una comunidad de hombres libres, exigiendo el respecto de los demás hombres, de los grupos sociales y del Estado, y con posibilidad de poner en marcha el aparato coactivo de Estado en caso de infracción (PÉREZ LUÑO, 1979, p. 43)1.

Ao longo dos tempos, diversas classificações dos direitos fundamentais foram desenvolvidas doutrinariamente, destacando-se a teoria geracional dos direitos fundamentais, a qual utiliza o critério da evolução histórica para caracterizá-los e individualizá-los. Daí a tríplice classificação desses direitos:

a) direitos fundamentais de primeira geração, os quais têm a liberdade como elemento caracterizador; b) direitos fundamentais de segunda geração, direitos identificados com a busca da igualdade material; c) direitos fundamentais de terceira geração, complexa estrutura de direitos que têm na solidariedade humana o elemento caracterizador (SCHÄFER, 2013, p. 101, grifo do autor $)^{2}$.

De toda forma, o que importa referir, neste momento, é que os direitos fundamentais, ancorados na liberdade, na igualdade e, posteriormente, na solidariedade, voltam-se, preponderantemente, para a proteção e a efetivação da dignidade da pessoa humana no seu mais amplo sentido. Essa dignidade da pessoa humana, enquanto elemento aglutinador dos direitos fundamentais, esteio teórico de uma constituição democrática, deve ser compreendida como um dever e como um limite da atividade estatal, razão pela qual se justifica a necessidade de uma concepção complexa, que contemple as diversas dimensões da realidade:

Temos por dignidade da pessoa humana a qualidade intrínseca e distintiva reconhecida em cada ser humano que o faz merecedor do mesmo respeito e consideração do Estado e da comunidade, implicando, neste sentido, um complexo de direitos e deveres fundamentais que assegurem a pessoa tanto contra todo e qualquer ato de cunho degradante e desumano, como venham a lhe garantir as condições existenciais mínimas para uma vida saudável, além de propiciar e promover sua participação ativa e co-responsável [sic] nos destinos da própria existência e da vida em comunhão com os demais seres humanos, mediante o devido respeito aos demais seres que integram a rede da vida (SARLET, 2012, p. 52).

Esta definição ressalta a ideia de dignidade a partir da cidadania consciente, crítica, criativa e comprometida com o bem-viver, vinculada ao constitucionalismo que se consolida com base na participação popular em torno dos direitos. 
Ainda é preciso dizer que, ínsito ao modelo democrático, está a norma de que os direitos fundamentais têm primazia sob quaisquer outros direitos, sendo considerados cláusulas pétreas, ou seja, os direitos já consagrados não podem ser objeto de supressão, total ou parcial.

Assim, pode-se afirmar que esse modelo de direitos fundamentais é o motor daquilo que se denomina interesse público, modificando o papel que o Estado desempenhava até o momento: o Estado deixa de ser fim em si mesmo e passa a ser meio de concretização dos direitos consagrados constitucionalmente.

É nesse cenário apresentado que o direito ao meio ambiente ecologicamente equilibrado passa, a partir de 1988, a ser considerado um direito fundamental e, assim, uma dimensão da dignidade da pessoa humana. Essa dimensão socioambiental se justifica já de início pela conexão que se estabelece, como dito, entre os direitos fundamentais e o meio ambiente, desde sua forma mais básica:

Do ponto de vista biológico, a dependência do homem em relação ao ambiente é total: o ser humano não pode sobreviver mais do que quatro minutos sem respirar, mais de uma semana sem beber água e mais de um mês sem se alimentar. $\mathrm{O}$ único local conhecido do universo no qual o homem pode respirar, tomar água e alimentar-se é a Terra. Nessa ótica o ambiente estaria intrinsecamente relacionado com os direitos à vida e à saúde (CARVALHO, E., 2011, p. 142).

Esta dimensão socioambiental surge diante de uma crise civilizatória grave, que pode ser chamada de ambiental, partindo-se da percepção da complexidade da definição de meio ambiente, devendo ser considerados os sujeitos, suas percepções e suas crenças neste processo de conceituação, uma vez que sua compreensão é indispensável para a apreensão das diferentes percepções do que seja meio ambiente em diferentes grupos. Nesse sentido, o Programa Nacional de Educação Ambiental (Pronea) estabeleceu, entre seus princípios,

[...] a concepção de meio ambiente em sua totalidade, considerando a interdependência sistêmica entre o meio natural e construído, o socioeconômico e o cultural, o físico e o espiritual, sob o enfoque da sustentabilidade (BRASIL, 2005).

Registre-se que a sustentabilidade apresenta-se como um processo que se preocupa em contemplar as dimensões econômica e cultural, integrando estas a:

[...] subsistência (garantindo a existência biológica); proteção; afeto; criação; produção; reprodução biológica; participação na vida social; identidade e liberdade. Portanto, sustentável não é o processo que apenas se preocupa com uma das duas dimensões, mas que contempla ambas, o que é um enorme desafio diante de uma sociedade que prima pelos interesses econômicos acima dos demais (LOUREIRO, 2012. p. 56). 
Nessa linha, são encontradas definições diversas de meio ambiente, conforme se esteja tratando do viés biológico, psicológico, econômico ou, ainda, jurídico. Defende-se que é preciso pensar o meio ambiente em sua complexidade, a partir de uma abordagem integradora dos diversos aspectos políticos, éticos, sociais, tecnológicos, científicos, culturais, econômicos e ecológicos. É nesse sentido também que deve ser lido o artigo 225, caput da Constituição federal, o qual estabelece que

Todos têm direito ao meio ambiente ecologicamente equilibrado, bem de uso comum do povo e essencial à sadia qualidade de vida, impondo-se ao Poder Público e à coletividade o dever de defendê-lo e preservá-lo para as presentes e futuras gerações (BRASIL, 1988).

Ao constitucionalizar tal direito, o legislador constituinte reconheceu a viabilidade do preceito de estabelecer um direito fundamental; eis que, nos termos postos, o direito ao meio ambiente equilibrado é direito essencial, verdadeiro desdobramento do direito à vida. Ou seja, há uma inexorável relação entre as condições ambientais necessárias à vida e a proteção dos valores ambientais. Assim, pode-se entender o meio ambiente como o conjunto das relações que fomentam e possibilitam a vida em todas as suas formas, porque é importante interpretar a dignidade da pessoa humana para além do olhar antropocêntrico que marca a legislação brasileira, alargando-se o espectro jurídico para qualquer forma de vida.

Além disso, a ideia de dignidade enquanto uma qualidade especial do ser humano - herança teórica de Kant, para quem a dignidade, sendo comum a todos, torna todos iguais - não se sustenta mais. Uma análise das relações sociais, econômicas e políticas mostra que a dignidade não se distribui igualmente, mas, pelo contrário, considerando outras questões valorativas, que envolvem, em apertada síntese, disputas de poder e a consequente lesão aos direitos fundamentais.

Nesse sentido, a própria ideia de dignidade, enquanto inerente a todo ser humano, é contraditória, o que revela um processo de tensão, uma vez que o fato de a Constituição federal estabelecer a dignidade da pessoa humana e, ao mesmo tempo, os direitos fundamentais para todos não garante o efetivo acesso a esses direitos. Logo, para que se dê esse acesso, é preciso ocorrer o tensionamento entre duas partes, do próprio sujeito, que se vê capaz de realizar os direitos, e da sociedade, que também vê no sujeito sua aptidão para o exercício desses direitos (STRELHOW, 2016). Há que se reconhecer que, para que esse tensionamento ocorra, faz-se necessário um processo de tomada de consciência que só pode acontecer dentro de um espaço de autonomia e liberdade.

Por essa razão, é que se defende que a ideia de dignidade deve estar relacionada à participação do sujeito de direitos em seus ambientes de forma reflexiva e crítica, espaço esse que se deve pautar por autonomia e liberdade. 
A EA traz as condições de possibilidade necessárias para que se promova esse espaço, até porque a EA é também, na perspectiva proposta, uma educação popular, uma vez que ela "deve ser libertadora, incentivar o lado crítico e dialógico para que todos tenham as mesmas oportunidades e acesso às informações" (PEREIRA; ALVARENGA; MARQUES, 2003, p. 191). Assim, para que se possa compreender a EA como esse espaço dialógico e crítico, é preciso também pensá-la na perspectiva da dignidade e dos direitos fundamentais.

No entanto, no Brasil, parece que o debate político da EA ainda não atingiu a expressão necessária, uma vez que se tem a impressão da ideia generalizada de que a EA se preocupa em promover uma mudança de comportamento individualista, como é o caso da reciclagem ou do controle do uso de água domiciliar, que são práticas não menos importantes, mas de reduzido poder emancipatório, uma vez que não realizam a transformação no conhecimento e na atuação social.

Por essa razão, parte-se, neste artigo, da concepção de uma EA emancipatória, como "instância formativa de sujeitos sociais, isto é, autores da própria história" (CARVALHO, I., 2011, p. 156). É uma educação voltada para colaborar com o sujeito, a fim de que reflita, criticamente, sobre as questões socioambientais e, assim, atue sobre elas. Propõe-se, portanto, pensar a EA em uma perspectiva crítica, que é a "de incluir uma dimensão social na questão ambiental que confere um posicionamento político, frente aos dilemas que a humanidade sofre" (DIAS, 2015, p. 125). Trata-se, assim, de um processo sociopolítico, cultural e pedagógico, voltado à cidadania.

Em outra perspectiva, pode-se dizer que o que se pretende é revigorar o sentido do ser a partir de uma ontologia hermenêutica na EA, retomando outros sentidos colonizados pela racionalidade instrumental (PEREIRA, 2016). Isso significa que, para além de um espaço/processo permanente para compreender e interpretar o mundo, a EA se apresenta também como um modo de ser. Assim, "a EA deve estar relacionada não somente com a reconstrução social para aliviar a exploração dos recursos naturais, mas também para evitar as injustiças sociais no processo dessa reconstrução" (SATO, 1997, p. 30).

No entanto, entende-se, nesta perspectiva, que a cidadania é meio - e não meta -, a ser construída a partir do processo de EA. Jacobi (2006, p. 431) comenta que, quando se pensa a EA voltada ao exercício da cidadania, o que se pretende é a consolidação de sujeitos cidadãos, isto é,

O desafio do fortalecimento da cidadania para a população como um todo, e não para um grupo restrito, se concretiza a partir da possibilidade de cada pessoa ser portadora de direitos e deveres e se converter em ator co-responsável na defesa da qualidade de vida. 
Entende-se, nessa toada, que destacar a dimensão política que se propicia a partir do espaço da EA desvela a necessidade de se pensar acerca do compromisso social com o bem comum, o que significa:

[...] tomar partido frente à realidade social, não permanecer indiferente diante da injustiça, da liberdade desprezada, dos direitos humanos violados, do trabalhador explorado; descobrir nos estudantes o gosto pela liberdade de espírito e despertar neles a vontade de resolver os problemas em conjunto, estimulando-os a desenvolver o sentimento de que são responsáveis pelo mundo e pelo seu destino, encaminhando-os a uma ação militante (GUTIÉRREZ, 1984, p. 13).

Dessa forma, uma EA é definida como um compromisso político e ético do indivíduo consigo mesmo, com o outro e com o meio ambiente, uma EA cidadã. A escolha da Educação Ambiental Crítica se apresenta como a única, tendo em vista a necessidade de refletir acerca dos aspectos socioambientais das relações humanas, isto é, das relações estabelecidas entre os indivíduos e com o ambiente onde se inserem, para compreender, refletir criticamente e agir. Trata-se da crítica à racionalidade instrumental, de uma virada epistemológica, enfim, de um projeto emancipatório.

É por essa razão que se defende que a Educação Ambiental Crítica é um processo educativo que se volta para a cidadania, fornecendo "os elementos para a formação de um sujeito capaz tanto de identificar a dimensão conflituosa das relações sociais que se expressam em torno da questão ambiental quanto de posicionar-se diante desta" (CARVALHO, I., 2011, p. 163).

Mas, afinal, a questão que se coloca é por que esta EA, que traz as condições de possibilidade para a consolidação da cidadania, no Brasil, anda a passos vagarosos. Para que se compreenda esse dilema ético-político, é preciso entender o caminho da cidadania no Brasil.

\section{A subcidadania no Brasil como óbice à consolidação democrática}

O conceito de cidadania, pode-se dizer, é um conceito histórico e complexo, uma vez que envolve múltiplas dimensões, e, ainda, deve ser analisado de acordo com o tempo e o espaço em que é considerado. Arendt já afirmava que a cidadania poderia ser definida como

O direito a ter direitos, pois a igualdade em dignidade e direitos dos seres humanos não é um dado. É um construído da convivência coletiva, que requer o acesso ao espaço público. É este acesso ao espaço público que permite a construção de um mundo comum através do processo de asserção dos direitos humanos (1989, p. 31). 
De certo modo, pode-se dizer que o conceito de cidadania está ligado aos direitos e aos deveres que definem a vida em sociedade. Especialmente nos séculos XVIII e XIX, na modernidade, a cidadania deriva do pacto constitucional que estabelece a sociedade política e, a partir disso, o vínculo entre os indivíduos, o Estado e a democracia. Não é por outro motivo que Bobbio (2004, p. 21) irá afirmar que "a democracia é a sociedade dos cidadãos, e os súditos se tornam cidadãos quando lhes são reconhecidos alguns direitos fundamentais". Isso porque, no período após a Segunda Guerra Mundial, o reconhecimento de direitos fundamentais, por meio da promoção de políticas públicas pertinentes, tem sido um critério de análise acerca da concretização da dignidade da pessoa humana.

Entretanto, como já foi dito, o fato de serem os direitos fundamentais constitucionalmente garantidos não significa sua aderência à realidade. No Brasil, isso fica muito claro. O déficit de concretização dos direitos fundamentais e, por consequência, da dignidade da pessoa humana e do próprio modelo democrático está colocado há muito no cenário nacional, apesar da Constituição federal, vigente há mais de trinta anos.

Ocorre que o processo de construção da cidadania no Brasil se deu às avessas. Historicamente, estabeleceu-se no país um projeto societário de índole conservadora e autoritária, tendo, desde sempre, as decisões políticas importantes - como a própria independência e a proclamação da República - sido tomadas por uma elite dominante, e não por uma ruptura revolucionária, como em muitos outros países. Assim, o brasileiro não se comportava como um cidadão, mas como um servo subserviente e dependente do poder instituído.

Isso fica ainda mais claro se se compreender qual é a concepção de um cidadão pleno. Doutrinariamente, diz-se que se considera cidadão pleno aquele indivíduo dotado de três dimensões de direitos: civis, políticos e sociais. Os direitos civis estão relacionados com a ideia de liberdade individual, sendo, portanto, os direitos à vida, à liberdade, à propriedade, à igualdade, etc. Os direitos políticos têm como fundamento a ideia de autogoverno e se consubstanciam na participação do cidadão nas decisões acerca da sociedade em que se insere. $\mathrm{E}$, por fim, os direitos sociais, cujo fundamento é a justiça social, garantem a participação dos cidadãos na riqueza coletiva, concretizada na educação, no trabalho, na saúde, etc.

T. S. Marshall (1967), autor inglês que estudou o fenômeno da cidadania especialmente na Inglaterra, apontou que essas dimensões, para além de uma ordem cronológica, guardam uma sequência lógica. Ou seja, os direitos políticos, para que ocorram, dependem da existência prévia dos direitos civis; eis que não há partici- 
pação na vida política sem que antes se garanta a liberdade individual. Por sua vez, os direitos sociais também dependem da existência prévia dos direitos políticos e civis, já que se voltam à redução das desigualdades e à garantia de um mínimo bem-estar social. Dessa forma, direitos sociais sem a consolidação anterior de direitos civis e políticos tendem a reproduzir um modelo autoritário. Nas palavras de José Murilo de Carvalho (2015, p. 220):

Na sequência inglesa, havia uma lógica que reforçava a convicção democrática. As liberdades civis vieram primeiro, garantidas por um Judiciário cada vez mais independente do Executivo. Com base no exercício das liberdades, expandiram-se os direitos políticos consolidados pelos partidos e pelo Legislativo. Finalmente, pela ação dos partidos e do Congresso, votaram-se os direitos sociais, postos em prática pelo Executivo. A base de tudo eram as liberdades civis. A participação política era destinada em boa parte a garantir essas liberdades. Os direitos sociais eram menos óbvios e até certo ponto considerados incompatíveis com os direitos civis e políticos [...]. Só mais tarde esses direitos passaram a ser considerados compatíveis com os outros direitos, e o cidadão pleno passou a ser aquele que gozava de todos os direitos, civis, políticos e sociais.

No Brasil, a construção da cidadania, todavia, não se deu dentro dessa sequência. Aqui, os direitos sociais tiveram mais ênfase e precederam os demais, ressaltando-se que esses foram estabelecidos em ambientes políticos, no mínimo, contraditórios. Nesse sentido, Carvalho (2015, p. 219) expõe que, inicialmente, foram definidos os direitos sociais, "implantados em período de supressão dos direitos políticos e de redução dos direitos civis por um ditador que se tornou popular". Num segundo momento, surgiram os direitos políticos, também durante a ditadura, quando "os órgãos de representação política foram transformados em peça decorativa do regime" (CARVALHO, 2015, p. 219). Por último, fechando a inversão da proposta de Marshall, revelam-se os direitos civis, dos quais muitos ainda continuam inacessíveis a uma grande camada da população.

Santos (2013, p. 119) já havia questionado se "há cidadãos neste país?", apontando, em seguida, que há uma cidadania mutilada, verdadeira forma de "não cidadania": "deixado ao quase exclusivo jogo do mercado, o espaço vivido consagra desigualdades e injustiças e termina por ser, em sua maior parte, um espaço sem cidadãos". É diante desse quadro desolador que a cidadania no Brasil precisa ser pensada e dialogada hermeneuticamente nesse espaço de EA. Não há como negar as escolhas históricas feitas, até porque são elas que hoje se traduzem nas limitações sociais do país.

O Estado Democrático de Direito, como modelo que prioriza os direitos fundamentais, pressupõe uma cidadania atuante, em que o cidadão se reconheça apto a 
reivindicar perante o governo, participando no exercício do poder político. Isso se dá, exatamente, pela garantia e pela concretização dos direitos fundamentais que asseguram o exercício da cidadania plena.

Destacam-se os chamados direitos de solidariedade ou fraternidade, os quais traduzem a massificação social vigente e os conflitos advindos dessa situação, uma vez que "não se destinam a pessoas determinadas ou a grupos de pessoas, mas têm por destinatário toda a coletividade, em sua acepção difusa, como o direito à paz, ao meio ambiente, ao patrimônio comum da humanidade" (SCHÄFER, 2013, p. 56).

Enfim, o Estado Democrático de Direito deve estabelecer as condições institucionais que assegurem a cidadania. Ora, a EA se constrói a partir da conscientização da população sobre as questões socioambientais e o incentivo à participação política em todas as suas dimensões. Essa participação é o exercício da cidadania. Ou seja, a EA é peça fundamental, porque permite, por meio da mobilização do indivíduo, desvelar seu papel dentro da sociedade, revelando que está apto a atuar coletivamente e exercer a cidadania, não só participando dos processos decisórios, mas também:

[...] tornando-se capaz de construir vínculos fortes e estáveis entre os membros de sua comunidade, tendo por fundamentos a unidade social, a aceitação, a solidariedade e o senso de um destino comum, porque nada adiantaria ser cidadão sem a perspectiva ou possibilidade de pôr em prática essa prerrogativa: a de exercer a cidadania (COSTA; TERRA, 2007, p. 48).

Portanto, pode-se dizer que o exercício da cidadania, possibilitado a partir do espaço da EA, agrega ainda outro elemento indispensável: a solidariedade social, a qual diz respeito "à relação de todas as partes de um todo, entre si e cada um perante o conjunto de todas elas" (COMPARATO, 2006, p. 577). Assim, a ideia de solidariedade está imbricada com a de comunidade, na perspectiva de pertencer e compartilhar, o que Casalta Nabais (2005, p. 84) traduz nas seguintes palavras:

A solidariedade pode ser entendida quer em sentido objetivo, em que se alude à relação de pertença e, por conseguinte, de partilha e de corresponsabilidade que liga cada um dos indivíduos a sorte e vicissitudes dos demais membros da comunidade, quer em sentido subjectivo e de ética social, em que a solidariedade exprime o sentimento, a consciência dessa mesma pertença à comunidade.

A solidariedade social, nesse sentido, de pertença, em que a harmonia social depende da preocupação de cada um com todos, é o elemento justificador da legitimidade de um Estado socialmente justo que efetivamente pugne pela dignidade da pessoa humana, concretizada, por sua vez, pelos direitos fundamentais constitucionalmente consagrados, tudo com o fim de promover a justiça social, da qual é instrumento a EA. 


\section{A educação ambiental como condição de possibilidade da justiça social}

Não restam dúvidas de que o cenário de desigualdade no Brasil, assim como no resto do mundo, é avassalador. José Bonifácio afirmou em representação enviada à Assembleia Constituinte de 1823 que "a escravidão era um câncer que corroía nossa vida cívica e impedia a construção da nação" (CARVALHO, 2015, p. 228). Nos tempos atuais, pode-se dizer que é a desigualdade que impede a consolidação da democracia.

O Brasil está entre os países mais desiguais, situação agravada por déficits em matéria de direitos econômicos e sociais. Em estudo produzido pela Oxfam Brasil (2017), entre os dados apurados, percebeu-se que níveis extremos de desigualdade econômica coexistem com pobreza generalizada: a concentração de renda do $1 \%$ dos brasileiros no topo é a maior do mundo. Os seis brasileiros, todos homens, mais ricos têm a mesma riqueza que os $50 \%$ mais pobres da população. Enquanto isso, afirma o estudo, 16 milhões vivem na pobreza, e mais de $50 \%$ estão vulneráveis a entrar na pobreza. A tabela seguinte ilustra este cenário:

Tabela 1 - A desigualdade econômica

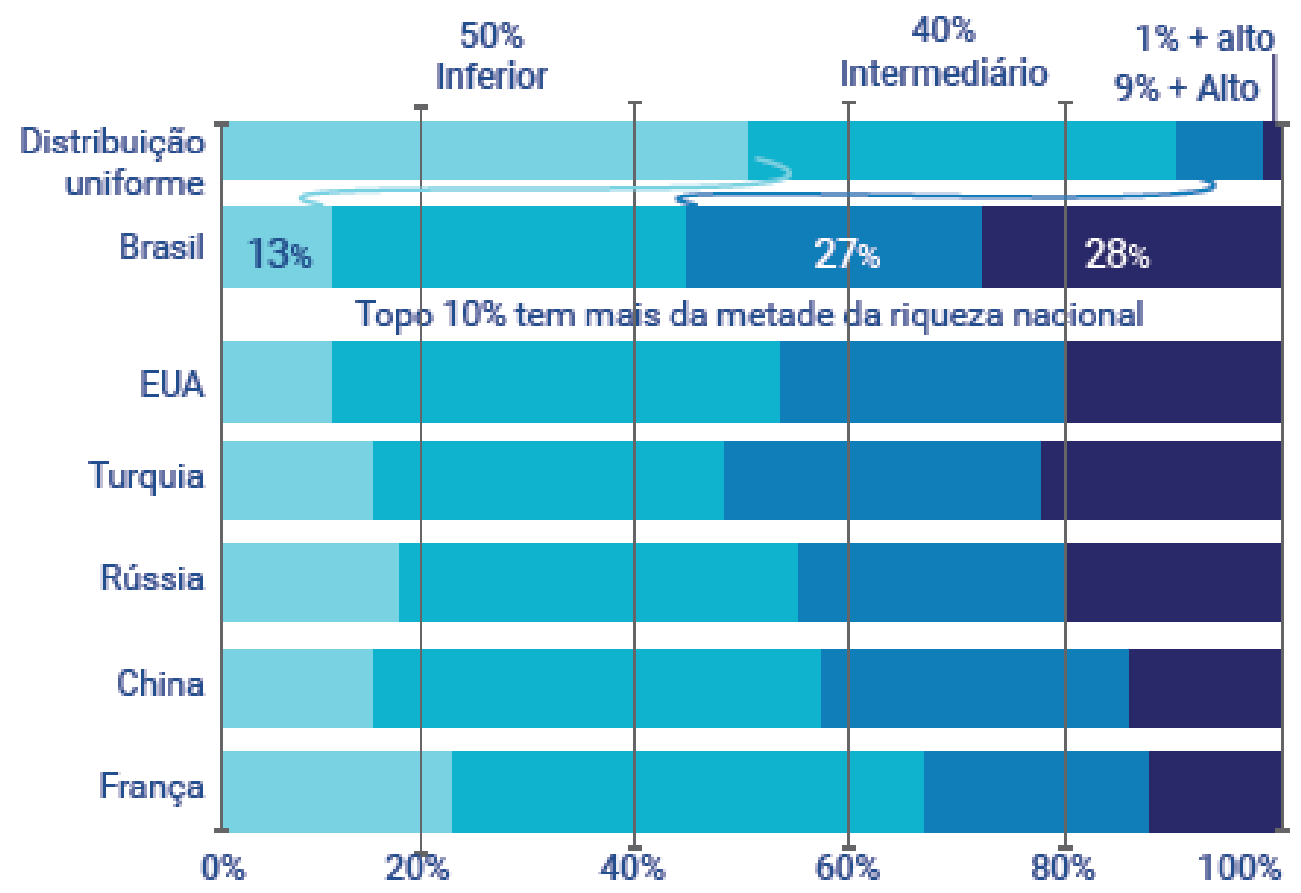

Fonte: Oxfam Brasil (2017). 
Este contexto de desigualdade econômica somado às medidas de austeridade, que foram adotadas pelo governo nos últimos tempos, aumentam ainda mais a desigualdade e a miséria, especialmente porque os maiores cortes orçamentários afetaram sobremaneira os direitos humanos, entre outros, conforme se pode observar nas variações orçamentárias nominais de programas selecionados do Brasil, no período compreendido entre 2014 e 2017 :

Figura 1 - A queda de investimentos nas políticas públicas sociais

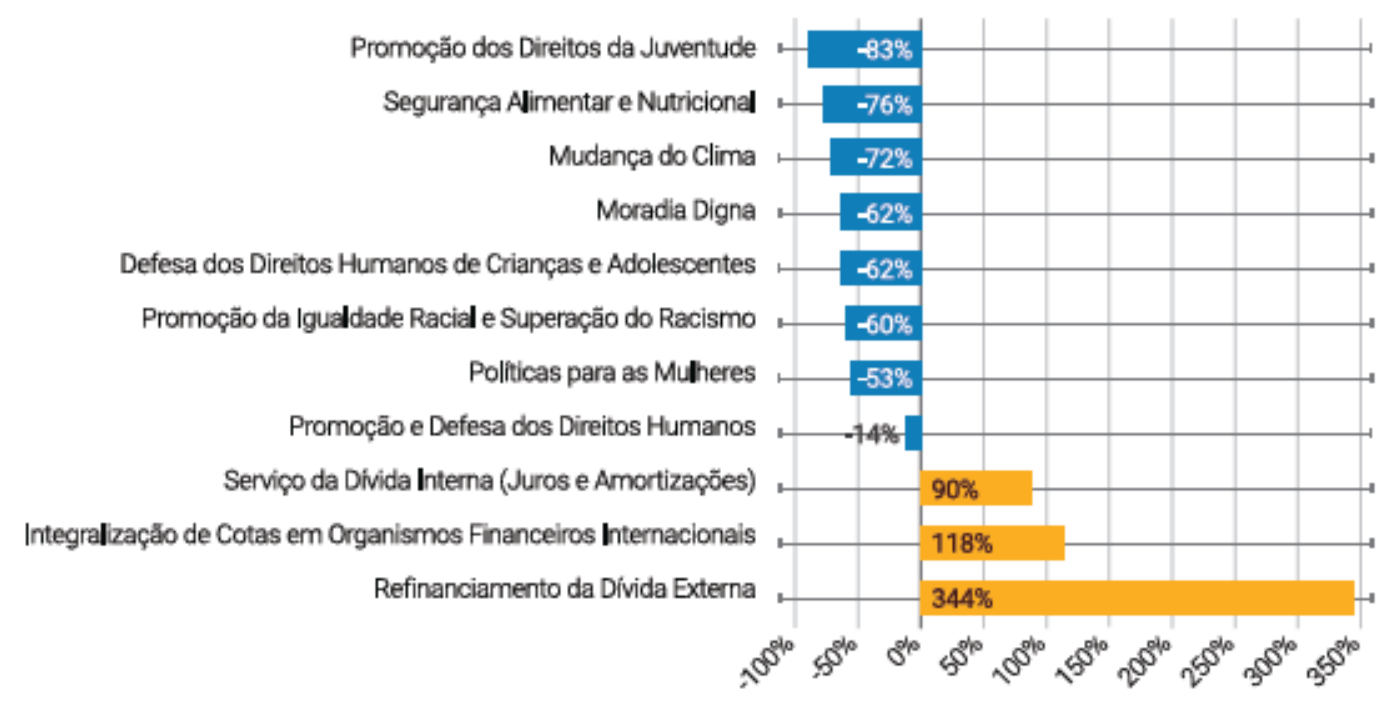

Fonte: Oxfam Brasil (2017).

Aliás, o cenário futuro não é promissor, uma vez que o teto de gastos estabelecido por estas medidas de austeridade irá reduzir, consideravelmente, os investimentos em áreas consideradas fundamentais, como a saúde e a educação. Isto apenas confirma que são as desigualdades as verdadeiras aniquiladoras da vida em sociedade.

É diante deste panorama, portanto, que é preciso pensar a justiça social. Isso porque a medida da justiça social, a qual admite variadas interpretações, mesmo no campo teórico, é a igualdade, valor que orienta políticas para a construção de uma sociedade mais solidária, justa e livre. Este valor, por sua vez, é conquistado pelo agir transformador dos agentes sociais em seus campos correspondentes, uma vez que a igualdade diante da lei não é suficiente, porque significa tão somente a obrigatoriedade de todos de cumprir a lei, mas não problematiza a realidade de 
desigualdade posta. Não é outro o sentido da afirmação de Marx (2012) de que o direito não teria que ser igual, mas desigual, porque as distorções promovidas pelo modelo econômico só podem ser corrigidas pelo Estado, estando aí o Direito como instrumento a serviço não do Estado, mas da sociedade, enquanto promotor de uma justiça distributiva e, portanto, corretiva.

Tradicionalmente, a ideia de justiça social se traduz como distribuição justa dos bens, como saúde, educação, liberdade, riqueza, etc. Parte-se neste estudo da concepção de justiça como um fim do Estado, como uma norma constitucional. Junkes (2005, p. 533) propõe a sistematização dos aspectos associados à noção jurídica em quatro grupos, quais sejam:

a) grupo de preceitos relacionados preponderantemente à garantia e à promoção da dignidade em favor de todas as pessoas; b) grupo de preceitos relacionados preponderantemente à garantia e à promoção do valor liberdade a todos os membros da sociedade; c) grupo de preceitos relacionados preponderantemente à garantia e à promoção da equalização de oportunidades a todos; d) grupo de preceitos relacionados preponderantemente à garantia e à promoção da redução dos desequilíbrios sociais em favor dos membros ou setores mais inferiorizados da comunidade política.

Não restam dúvidas de que dois aspectos são importantes enquanto elementos de justiça social: a reflexão sobre os efeitos distributivos de uma estrutura institucional sobre as diferentes oportunidades de vida dos membros de uma comunidade, assim como a reflexão sobre o acordo acerca dos princípios que devem orientar essa mesma estrutura (Miller, 1998). A grande questão, e este é o óbice, é como transformar esse pacto teórico em ação. E é nesse momento que se defende a EA como o espaço que estabelece as condições de possibilidade para o exercício da cidadania, a qual está intimamente ligada à justiça social. Até porque a EA contempla múltiplas dimensões - ambientais, sociais, políticas, culturais - que não podem ser obscurecidas. A EA é, assim, o espaço adequado para que se realize essa denúncia à negligência consciente do Estado para com a questão socioambiental; enfim, para com a dignidade da pessoa humana. Estes aspectos são muito importantes, porque,

Na poética da Educação Ambiental, a atenção à degradação ambiental muitas vezes deixa escapar a injustiça social. Por isso é preciso reivindicar a consciência reflexiva de que toda miséria humana está intrinsecamente relacionada com os impactos ambientais. Teremos o enorme desafio de transformar a poética em sua dimensão política, pois a história da civilização do Homo Sapiens já comprovou que os prejuízos dos danos ambientais recaem sempre nas camadas economicamente desfavorecidas (SATO; PASSOS, 2006, p. 23).

É a EA uma educação política, porque questiona as certezas absolutas e dogmáticas, comprometendo-se com uma cidadania plena na busca por uma convivên- 
cia digna entre os seres humanos e com o ambiente onde se insere. A EA, neste panorama, apresenta-se como o espaço dialógico apto a propiciar o questionamento dos paradigmas do conhecimento e do modelo de sociedade moderna, apresentando a necessidade de uma racionalidade outra, "orientada por novos valores e saberes; por modos de produção sustentados em bases ecológicas e significados culturais; por novas formas de organização democrática” (LEFF, 1999, p. 112).

Daí porque se reforça a convicção de que a EA é um ser-com, e nesse sentido ela é também uma educação popular, porque se constitui como um espaço para uma prática de conscientização voltada à transformação social (PEREIRA; ALVARENGA; MARQUES, 2003).

Em outras palavras, uma educação cujos conceitos podem ajudar na construção de uma sólida cidadania, ancorada numa visão crítica e transformadora, "no sentido do desenvolvimento da ação coletiva necessária para o enfrentamento dos conflitos socioambientais" (LAYRARGUES, 2006, p. 87-88). Enfim, uma EA que, enquanto projeto emancipatório, cria condições para reflexão e atuação em busca de justiça social, em que a cidadania é meio para essa concretização que há muito se anseia.

\section{Considerações finais}

A partir dos argumentos apresentados neste texto, observou-se que é a EA um espaço político adequado para que se estabeleçam as reflexões e o agir necessários para a construção de uma outra realidade. É, portanto, um espaço para a concretização da justiça social.

Não mais tendo por base uma concepção de falso equilíbrio, mas reconhecendo as contradições e os conflitos éticos, políticos e socioambientais, acredita-se que a Educação Ambiental Crítica pode contribuir não apenas no reconhecimento de garantias e lutas, mas também no sentido que essas políticas assumiram e assumem em defesa da vida.

Assim como Paulo Freire, quando do seu retorno do exílio, acredita-se que é preciso reaprender o Brasil pós-golpe de 2016. Nesse esforço hermenêutico de reaprendizagem, os diferentes campos do saber, além de uma avaliação sobre as escolhas feitas, devem ter a coragem de reforçar os reconhecimentos construídos. Nesse sentido, deve-se reafirmar as convicções pela Educação Ambiental Crítica a partir de uma sociedade, de uma escola, de uma universidade popular e afirmativa 
que reconheça as questões ambientais a partir da perspectiva do ambiente inteiro, e não apenas do meio/ambiente.

O projeto antagônico a este já é conhecido. Ele tem a ênfase no lucro e no poder a qualquer custo; no agronegócio e nos agrotóxicos; na usurpação das reservas indígenas para exploração de minérios; na afirmação de um governo para os mais favorecidos; e no não reconhecimento das diferenças - além da condenação e do ataque aos pensadores com perspectivas crítico-progressistas.

Pelo horizonte da EA, pode-se encontrar espaços para continuar se organizando, denunciando e resistindo a esse projeto maior e buscando possibilidades viáveis de construção de um projeto coletivo e emancipatório com justiça social. Ainda que de modo incipiente, já houve experiências que reafirmam e demonstram as possibilidades de um projeto emancipatório. Nesse caso, pensa-se que é necessário a reinvenção dos movimentos sociais populares. Mas este pode ser o tema de outro artigo.

\section{Notas}

1 Tradução livre: faculdade que a norma atribui de proteção à pessoa no que se refere a sua vida, liberdade, igualdade, a sua participação política e social ou a qualquer outro aspecto fundamental que afete o seu desenvolvimento integral como pessoa em uma comunidade de homens livres, exigindo o respeito dos demais homens, dos grupos sociais e do Estado, e com possibilidades de colocar em funcionamento o aparato coativo estatal em caso de infração.

2 Já existem doutrinadores defendendo a existência da quarta, da quinta e da sexta gerações de direitos fundamentais.

\section{Referências}

ARENDT, Hannah. Origens do Totalitarismo: anti-semitismo, imperialismo, totalitarismo. São Paulo: Companhia das Letras, 1989.

BOBBIO, Norberto. A era dos direitos. Rio de Janeiro: Elsevier, 2004.

BRASIL. Constituição (1988). Constituição Federal, de 05 de janeiro de 1988. Constituição da República Federativa do Brasil. Brasília, 05 jan. 1988. Disponível em: http://www.planalto.gov. br/ccivil_03/constituicao/constituicao.htm. Acesso em: 10 fev. 2019.

BRASIL. Ministério do Meio Ambiente, Diretoria de Educação Ambiental, Ministério da Educação, Coordenação Geral de Educação Ambiental. Programa Nacional de Educação Ambiental. Brasília: Ministério do Meio Ambiente, 2005.

CARVALHO, Edson Ferreira de. Meio ambiente e direitos humanos. Curitiba: Juruá, 2011.

CARVALHO, José Murilo de. Cidadania no Brasil: o longo caminho. Rio de Janeiro: Civilização Brasileira, 2015. 
CARVALHO, Isabel Cristina de Moura. Educação ambiental: a formação do sujeito ecológico. São Paulo: Cortez, 2011.

CASALTA NABAIS, José. Estudos de Direito Fiscal: por um estado fiscal suportável. Coimbra: Almedina, 2005.

COMPARATO, Fábio Konder. Ética: direito, moral e religião no mundo moderno. São Paulo: Companhia das Letras, 2006.

COSTA, Marli M. da; TERRA, Rosane B. M. A Educação Ambiental para o exercício da Cidadania. In: GORCZEVSKI, Clóvis (org.). Direitos humanos, educação e meio ambiente. Porto Alegre: Evangraf, 2007. p. 31-52.

DIAS, Bárbara de Castro. Educação Ambiental Crítica: para além da teoria crítica, algumas contribuições da teoria pós-crítica. Revista Ciências \& Ideias, Nilópolis, v. 6, n. 1, p. 124-132, jun. 2015. Entrevista com Michèle Sato. Disponível em: http://revistascientificas.ifrj.edu. br:8080/revista/index.php/reci/article/view/465. Acesso em: 05 fev. 2019.

GADAMER, Hans-Georg. Verdade e método I: traços fundamentais de uma hermenêutica filosófica. Petrópolis: Vozes, 2013.

GUTIÉRREZ, Francisco. Educação como práxis política. São Paulo: Summus, 1984.

JACOBI, Pedro. Meio ambiente e educação para a cidadania: o que está em jogo nas grandes cidades? In: SANTOS, José Eduardo dos; SATO, Michèle (org.). A contribuição da educação ambiental à esperança de pandora. São Carlos: Rima, 2006. p. 423-438.

JUNKES, Sérgio Luiz. A justiça social como norma constitucional. Resenha Eleitoral- Nova Série, Florianópolis, v. 12, n. 1, p. 527-552, jun. 2005. Semestral. Disponível em: https://www. tre-sc.jus.br/site/resenha-eleitoral/edicoes-impressas/integra/2012/06/a-justica-social-como-norma-constitucional/indexe466.html?no_cache=1\&cHash=aa3c3d7c9a3d443f55cddb5295ac22 7b. Acesso em: 08 fev. 2019.

LAYRARGUES, Philippe Pomier. Educação para a Gestão Ambiental: a cidadania no enfrentamento político dos conflitos socioambientais. In: LOUREIRO, Carlos Frederico Bernardo; LAYRARGUES, Philippe Pomier; CASTRO, Ronaldo Souza de (org.). Sociedade e meio ambiente: a educação ambiental em debate. São Paulo: Cortez, 2006. p. 87-155.

LEFF, Enrique. Saber ambiental - sustentabilidade, racionalidade, complexidade, poder. Petrópolis: Vozes, 1999.

LOUREIRO, Carlos Frederico Bernardo. Sustentabilidade e educação: um olhar da ecologia política. São Paulo: Cortez, 2012.

MILLER, David. Perspectivas de justiça social. Análise Social, Lisboa, v. 33, p. 323-339, 1998. Disponível em: http://analisesocial.ics.ul.pt/documentos/1221842899L0bNW8jz1Lo32LV0.pdf. Acesso em: $1^{\circ}$ mar. 2019.

OXFAM BRASIL. Teto de gastos: estudo revela queda de até $83 \%$ em políticas públicas para área social. 2017. Disponível em: https://www.oxfam.org.br/noticias/teto-de-gastos-estudo-revela-queda-de-ate-83-em-politicas-publicas-para-area-social. Acesso em: 03 mar. 2019. 
PEREIRA, Vilmar Alves; ALVARENGA, Bruna Telmo; MARQUES, Paola Reyer. A contramarcha de uma petiana conexista em um pré-universitário popular. In: PEREIRA, Vilmar Alves; DIAS, José Roberto de Lima; ALVARENGA, Bruna Telmo. Educação popular e a pedagogía da contramarcha: uma homenagem a Gomercindo Ghiggi. Passo Fundo: Méritos, 2003. p. 187-206.

PEREIRA, Vilmar Alves. Ecologia Cosmocena: a redefinição do espaço humano no cosmos. Juiz de Fora: Garcia Edizioni, 2016.

PÉREZ LUÑO, Antonio Enrique. Delimitación conceptual de los derechos humanos. In: PÉREZ LUÑO, Antonio Enrique et al. Los derechos humanos: significación, estatuto jurídico y sistema. Sevilla: Publicaciones Universidad de Sevilla, 1979. p. 13-46.

SANTOS, Milton. O espaço da cidadania e outras reflexões. Porto Alegre: Fundação Ulysses Guimarães, 2013.

SATO, Michèle. Educação para o ambiente amazônico. 1997. 246 f. Tese (Doutorado em Ciências) - Programa de Pós-Graduação em Ecologia e Recursos Naturais, Centro de Ciências Biológicas e da Saúde, Universidade Federal de São Carlos, São Carlos, 1997. Disponível em: www. lapa.ufscar.br/pdf/tese_doutorado_michele_sato.pdf. Acesso em: 15 fev. 2019.

SATO, Michèle; PASSOS, Luiz Augusto. Pelo prazer fenomenológico de um não-texto. In: GUIMARÃES, Mauro (org.). Caminhos da Educação Ambiental: da forma à ação. Campinas: Papirus, 2006. p. 17-30.

SARLET, Ingo W. Dignidade da pessoa humana e direitos fundamentais na Constituição federal de 1988. Porto Alegre: Livraria do Advogado, 2012.

SCHÄFER, Jairo. Classificação dos direitos fundamentais: do sistema geracional ao sistema unitário - uma proposta de compreensão. Porto Alegre: Livraria do Advogado, 2013.

STRELHOW, Thyeles Moratti Precilio Borcarte. A constituição da dignidade humana: aportes para uma discussão pós-metafísica. Cadernos Teologia Pública, São Leopoldo, v. 13, n. 119, p. 3-28, 2016. 